\section{Cultural Narratives of the Present and the Past}

\section{Dr Natalya Zavyalova ${ }^{\dagger}$}

The current issue is intended to provide the readers with a guide to the leading theories in the field of history, natural languages, tolerance, theatre, and many other areas of humanities and liberal arts. We are grateful to all our authors for their unfailing commitment and wise counsel. At the heart of all the materials presented in the issue is the idea of cultural communication which is given in all the known forms of transmission of cultural meanings: graphic, acoustic, visual. The central question of the entire issue is the role of local cultures in India, Kazakhstan, Azerbaijan, and Russia in the modern global world.

There is a growing body of literature which recognises the importance of culture and communication. Experts believe that communication is a social action, conditioned situationally, where culture is equated with communication and vice versa. Of much importance is the fact that the study of communication makes it possible to prepare the social unconscious accessible for analysis. Our primary concern is the assumption that the analysis of communication fills the social reality with specific content and eliminates the need to search for a peculiar sociological basis for its analysis.

Interactions and communications play a pivotal role in constructing social reality and perform the functions of interrelated subjects. Considering society through the prism of communication, we are moving into the domain of language and culture. The translation of culturally significant information occurs through the language of historical events, acts of tolerance and justice, speech interactions, containing the aggregate universal

\footnotetext{
${ }^{+}$Associate Professor, The Institute of Liberal Arts and Humanities, UrFU, 620002, Ekaterinburg Russian Federation, Email: N.A.Zavialova@urfu.ru (c) 2018 Zavyalova. This is an Open Access article distributed under the terms of the Creative Commons Attribution License (http://creativecommons.org/licenses/by/2.0), which permits unrestricted use, distribution, and reproduction in any medium, provided the original work is properly cited.

Within the framework of the culturalphilosophical direction, let us note the
}

elements that are understandable to the majority.

An increasingly large number of researchers concentrate on the problem of globalisation. In new global culture, different types of communication perform the fundamental role of bringing people closer in any cultural process. A key instrument of a new global culture is the idea that it materialises itself in numerous objectified forms of the past and the present, but its real existence is manifested in cooperative actions, informational and meaningful interaction between people. In this case, it is necessary to speak about global universes of culture, which are mastered by everyone in the process of socialisation, in a certain epoch, thereby creating a specific system of coordinates. Observers construct the futuristic images of a global society where people get increasingly focused on a single language and culture. However, local cultures perform an incredibly prominent role and become a vital object of inquiry.

The cultures of India, Kazakhstan, Azerbaijan, and Russia have been playing a key role in the implementation of the interaction of society members from ancient times. Scientists trace the direct connection between the formation of communicative channels and the emergence of culture in the first human collectives. In our opinion, the most powerful idea about local cultures is the fact that they do not only promote the design and preservation of local societies as such but, primarily, they manifest themselves as creators of the societies they represent. The importance of culture as a distinguishing feature of man from the animal world, as well as the super biological nature of culture is fixed in the ideas of many prominent scholars of today. The description of the entire universe is impossible without attention to local cultures and their constitutive elements. 
attention of scientists to communication as a component of cultural patterns, the mechanisms of which were laid down in the arguments of Patanjali, Plato, Heraclitus, Aristotle. New time put forward the concept of V. von Humboldt, based on the understanding of the "inner form" and "language worldview". Continuing I. Kant's interpretations of the symbolic nature of the language, E. Cassirer puts forward his own subject of the philosophy of culture: the product of the symbolic human activity, mediated by the symbolism of speech. The scholar defined the place of culture as a spiritual centre, the core of spiritual ties. The increased attention to the essence of culture leads us to various spheres of human activities, ranging from theatre to politics, where culture helps us understand social and political implications.

Besides the description of global and local trends in the development of traditional cultures in India, Kazakhstan, Azerbaijan, and Russia we set the task of identifying the connection between the past and the present cultures through narratives at the stage of modern societies. It can be concluded that the study of the past and the present narratives are no less significant in the process of learning about cultures than an acquaintance with recognised works of art.

Cultural narratives are formed in the historical experience of a social group and continuously function as vital heritage. They are transferred and mastered by actors in the processes of socialisation and inculturation and are not constructed from the personal experience of the individual. Cultural narratives are coded in the collective, rather than individual characters. Culture, objectified in narratives, is extremely important for the formation of a nation, among the main features of which is the presence of a language as the main carrier and repeater of culture. Culture genesis manifests itself through a narrative in the process where culture is included in the language, since it is modelled in the text.

Recently there has been a renewed interest in the cultural area as a field of people's interaction. Historic, social, religious values, psychological attitudes, and ethnic features prevail here. In the cultural space, relations between people are unfolding; natural hierarchies are formed. Culture has long been a question of great interest in a wide range of fields. Cultural findings allow us to identify both the collective patterns of the understanding of everyday life and refer to the statements of individuals illustrating their own unique existential experiences. The systems of group cultural relations are integral parts which outline the landscapes of leaders, slaves, and freemen. The social domain is the context of cultural unities and wars, and it should be considered most carefully. 